\title{
The Correlation between Small Intestinal Bacteria Overgrowth and Dendritic Cells Phenotype and Function in Cirrhotic Patients with Hepatitis B
}

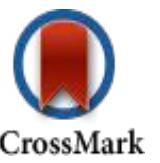

\author{
Ying Jie MA ${ }^{*}$, Xiao GAO², Xin Peng WEI ${ }^{2}$, Li YANG ${ }^{1}$, Ji Ao HAN ${ }^{1}$, Zhi Ling WANG ${ }^{1}$, Li HAN ${ }^{1}$ \\ ${ }^{1}$ Department of Gastroenterology, Zhengzhou People's Hospital, Zhengzhou Institute of Liver and Gastrointestinal Disease, Zhengzhou, \\ China \\ ${ }^{2}$ Department of Graduate, Xinxiang Medical University, Xinxiang, Henan Province, China
}

*Corresponding author: Ying Jie MA, Department of Gastroenterology, Zhengzhou People's Hospital, Zhengzhou Institute of Liver and Gastrointestinal Disease, Zhengzhou 450003, Henan Province, China, E-mail: mayingjie19@sina.com

Received date: January 09, 2016

Accepted date: January 22, 2016

Published date: January 25, 2016

Citation: Ying, M.A., et al. The Correlation between Small Intestinal Bacteria Overgrowth and Dendritic Cells Phenotype and Function in Cirrhotic Patients with Hepatitis B. (2016) J Gastrointest Disord Liver Func 1(2): 38- 42.

\begin{abstract}
Objective: To investigate the relationship between dendritic cells (DCs) and small intestinal bacteria overgrowth (SIBO) in cirrhotic patients with hepatitis B.

Methods: Flow cytometry was used to analyze the phenotype of peripheral blood DCs in 47 cirrhotic patients with hepatitis B and 15 healthy controls. Small intestinal bacterial overgrowth was determined by lactulose hydrogen breath test (LHBT). A basal breath hydrogen $>20 \mathrm{ppm}$ or arise by $>12 \mathrm{ppm}$ above baseline following lactulose administration was taken as positive test. LHBT aggregate value, as another indicator to evaluate the growth of the small intestinal bacteria, is the sum of the LHBT within 90 min. Plasma total bilirubin and plasma albumin were measured in all subjects. Data analysis was using SPSS 17.0.
\end{abstract}

Results: Of the 47 cirrhotics, $22(46.8 \%)$ had SIBO, compared to healthy controls $(6.7 \%$; $\mathrm{P}=0.005)$. The prevalence of SIBO increased with ChildPugh classification of cirrhosis (A 18.2\%, B 43.8\% and C 65.0\%). The prevalence of SIBO in cirrhotic patients of ChildPugh class $\mathrm{B}$ and $\mathrm{C}$ was significantly higher than that of healthy controls $(\mathrm{P}=0.037 ; \mathrm{P}=0.001)$. While the prevalence of SIBO in cirrhotic patients of ChildPugh class A was no statistically significant than that of healthy controls $(\mathrm{P}=0.556)$. The prevalence of SIBO in cirrhotic patients of decompensatory phase was significantly higher than that of compensatory phase $(\chi 2=4.727$, $\mathrm{P}=0.030)$. The plasma total bilirubin was positively correlated with LHBT aggregate value $(\mathrm{r}=0.907, \mathrm{P}=0.000)$, While plasma albumin was negatively correlated $(\mathrm{Ir}=0.810 \mathrm{P}=0.000)$. The expressions of CD1a, CD80, CD83 on the surface of DCs in cirrhotic patients were all significant lower than that in healthy controls $(\mathrm{P}<0.05)$, while the expression of HLADR was no statistically significant than that in healthy control. The expressions rate of CD80, CD83, CD1a and HLADR on the DCs surface in SIBO positive cirrhotic patients were lower than those in SIBO negative $[(17.22 \pm 2.08) \% v s .(22.13 \pm 2.34) \%,(24.65 \pm 1.47) \% v s$. ( $34.52 \pm$ $2.84) \%,(14.05 \pm 1.33) \%$ vs. $(17.40 \pm 3.22) \%,(81.47 \pm 7.56) \%$ vs. $(70.15 \pm 6.32) \% ;(\mathrm{P}<0.05)]$.

Conclusions: The prevalence of SIBO is correlated with severity of cirrhosis. The phenotype and function of peripheral blood DCs in cirrhotic patients with hepatitis B is associated with the presence of SIBO. 


\section{Introduction}

DCs are sparsely, but widely distributed professional antigen presenting cells (APC). According to the maturity status is divided into precursor phase, immature DCs and mature DCs. DCs originated from pluripotent hematopoietic stem cells. Precursor phase DCs from bone marrow to peripheral blood, widely distributed in many parts of our body. Immature DCs capture antigens in the peripheral tissues, migrate through the lymph to the lymph nodes, developed into mature DCs, where they present their captured antigens to $\mathrm{T}$ cells $\mathrm{s}^{[1,2]}$. DCs function is different in different differentiation phase. The mature DCs slowly loss of the ability in capture, processing and deal with the antigen and obtain the ability presentation of antigens to $T$ cells during immune response. Thus, DCs are critical mediators of both innate and adaptive immune response. Hepatitis B cirrhosis patients have different degrees, various forms of DCs anomalies. The study found that the number and functional of DCs decline and mature obstacles in patients with chronic hepatitis B, which lead to antigen presenting function of DCs defect. DCs couldn't effectively present antigens to $\mathrm{T}$ cells during immune response. The organism does not adequately clear hepatitis B virus (HBV) and develop into liver fibrosis, liver cirrhosis ${ }^{[3,4]}$. The portal hypertension, liver malfunction, hyperemia and edema of intestinal mucosa, motility disturbance, enterohepatic circulation of cholate disturbance in cirrhosis affect the type of intestinal bacteria and its ability to planting, metabolize, promote intestinal bacteria disorder and bacterial translocation. The research about the relationship between intestinal bacteria and DCs in cirrhotic patients with hepatitis B is rather little at present. In our study, we researched the correlation between small intestinal bacteria overgrowth and dendritic cells phenotype and function in cirrhotic patients with hepatitis B. The report is illustrated by the following.

\section{Materials and Methods}

\section{Subjects}

The study included 47 cirrhotic patients with hepatitis B consecutively hospitalized from June 2014 to September 2015. The severity of liver cirrhosis as defined by the ChildPugh classification. In our study, the ChildPugh class was an in 11 patients, $\mathrm{B}$ in 16 patients and $\mathrm{C}$ in 20 patients. The age of patients was $45.91 \pm 12.40$ years (range, 3275 years) and 30 patients were males. The diagnosis according to the guideline of prevention and treatment for chronic hepatitis B in $2010^{[5]}$. The control group consisted of 15 healthy volunteers, whose age was $42.25 \pm 14.18$ years (range, 2378 years) and 9 patients were males. Patients excluded this study were: patients with history of gastrointestinal surgery, renal failure, patients with the gastrointestinal dynamic diseases, such as diabetes and intestinal pseudo obstruction, and those who were using medications such as antibiotics, lactulose, acid inhibitory drugs and potentially affect intestinal motility in 2 weeks.

\section{SIBO assessment}

SIBO was determined by lactulose hydrogen breath test (LHBT). Our equipment is EC60 Gastrolyzer hydrogen gas detector, which is produced by Bedfont Company in England. The substrate is lactulose oral solution (duphalac). The subjects were asked to avoid milk products, bean products, crude fiber food and stimulate food the day before. On the evening before the breath test, they were gave the completely absorbed carbohydrates. The test day should be fasting. According to the operations manual, at the start of the test, fasting breath hydrogen was measured. Then the patients were asked to ingest $10 \mathrm{~g}$ lactulose dissolved in $200 \mathrm{~mL}$ water. LHBT was estimated by the collection of hydrogen excretion, every 15 minutes for 2 hours. An increase in hydrogen excretion, in parts per million (ppm), following lactulose administration, was calculated by subtracting the fasting value from the highest value of hydrogen excretion obtained. A basal breath hydrogen $>20 \mathrm{ppm}$ or arise by $>12 \mathrm{ppm}$ above baseline following lactulose administration was taken as positive test. The total volume of LHBT within 90 minutes (LHBT aggregate value) was calculated and used as another evaluation index of small intestinal bacteria growth.

\section{Main reagents and equipment}

RPMI 1640 medium and Lymphocyte Separation Medium were purchased from Beijing Solarbio Science \& Technology Company. rhIL4, rhGMCSF were purchased from PeproTech company. Mouse antihuman monoclonal antibody, APCCD83, was purchased from EBioscience Company. Mouse antihuman monoclonal antibodies, FITCCD80, PE CD1a, PerCpHLADR, were purchased from BD Biosciences. The plasma total bilirubin and plasma albumin determination reagent were purchased from Ningbo Meikang biological Polytron Technologies Inc. FACSAria flow cytometer was purchased from BD Biosciences.7600 automatic biochemical analyzer was purchased from Japan's Hitachi Limited.

Culture of DCs in peripheral blood: An amount of $20 \mathrm{~mL}$ of freshly heparinized peripheral blood was collected from each subject and diluted with same volume Hanks solution. And then add the diluted peripheral blood to lymphocyte separation medium along the tube wall. The sample was centrifuged at $2000 \mathrm{rpm}$ for 20 minutes at room temperature. The peripheral blood mononuclear cells (PBMC) between the plasma layer and lymphocyte separation medium, was aspirated into a new centrifuging tube with pipette. Cells were washed twice by five volume Hanks solution, and then centrifuged at $1800 \mathrm{rpm}$ and $1200 \mathrm{rpm}$ for 5 minutes. After centrifugation, the supernatant was discarded, and then the cells were mixed with RPMI 1640 medium. Cell density should be between 4 to $5 \times 10^{6}$ cells $/ \mathrm{ml}$. Cells were incubated for 2 hours at $37^{\circ} \mathrm{C}$ in $5 \% \mathrm{CO}_{2}$ incubator. Wash without adherent cells. Add AIMV serum free medium and cytokines (1000 $\mathrm{U} / \mathrm{ml} \mathrm{GMCSF}, 1000 \mathrm{U} / \mathrm{ml}$ IL4) to culture flask with adherent cells. Incubate the sample in $5 \% \mathrm{CO}_{2}$ incubator at $37^{\circ} \mathrm{C}$. Replace half of the medium and supplement cytokines after 3 days' culture and harvest the DCs after 7 days culture.

Analysis of the phenotype of DCs: After 7 day's culture, the cells were detached with an amount of $5 \mathrm{~mL}$ of PBS, centrifuged at $1000 \mathrm{rpm}$ for 8 minutes. And then washed the specific antigen in serum. Adjust the cell concentration to $1.5 \times 10^{6} \mathrm{cells} / \mathrm{ml}$. Subpackage to $1000 \mathrm{uL}$ per tube. Add $20 \mathrm{ul}$ mouse antihuman monoclonal antibody, PE CD1a, FITC CD80, APCCD83, PerCpHLA$\mathrm{DR}$, to the cells for 15 minutes at $37^{\circ} \mathrm{C}$, respectively. Washed with $3 \mathrm{ml}$ PBS twice, and then centrifuged at $1000 \mathrm{rpm}$ for 8 minutes. Adjust the cell concentration to $1.0 \times 10^{6} \mathrm{cells} / \mathrm{ml}$ with 
PBS. Flow cytometry analysis the phenotype of DCs.

\section{Statistical analyses}

The SPSS 17.0 statistical package was applied for data analysis. The results were expressed as mean with standard deviation (s.d.). Prevalence of SIBO between groups was analyzed using chisquare test or Fisher's exact test. Prevalence of expressions rate of CD1a, CD80, CD83 and HLADR on the surface of DCs between groups were analyzed using chi-square test. The relationship between LHBT aggregate value and biochemical index was analyzed using Pearson correlation analysis. A value of $\mathrm{P}<0.05$ was taken as significant.

\section{Results}

The prevalence of SIBO and the severity of cirrhotic of the 47cirrhotics, $22(46.8 \%)$ had SIBO, compared to healthy controls $(6.7 \% ; \mathrm{P}=0.005)$. The prevalence of SIBO increased with ChildPugh classification of cirrhotic (A18.2\%, B 43.8\% and $\mathrm{C} 65.0 \%$ ). The prevalence of SIBO in cirrhotic patients of ChildPugh class $\mathrm{B}$ and $\mathrm{C}$ was significantly higher than that of healthy controls $(\mathrm{P}=0.037 ; \mathrm{P}=0.001)$. While the prevalence of SIBO in cirrhotic patients of ChildPugh class A was no statistically significant than that of healthy controls $(P=0.556)$. The prevalence of SIBO in cirrhotic patients of loss compensatory phase was significantly higher than that of Compensatory phase $\left(\chi^{2}=4.727, \mathrm{P}=0.030\right)$, (Table 1). The biochemical index and LHBT aggregate-value in cirrhotic patients The plasma total bilirubin was positively correlated with LHBT aggregate-value, While plasma albumin was Negatively correlated with LHBT aggregate-value $(\mathrm{r}=0.907, \mathrm{P}=0.000, \mathrm{r}=-0.810, \mathrm{P}=$ $0.000)$, (Figure1). SIBO and DCs phenotype the expressions of CD1a, CD80, CD83 on the surface of DCs in cirrhotic patients were all significant lower than that in healthy controls $(\mathrm{P}<0.05)$, while the expression of HLA-DR was no statistically significant than that in healthy control. The expressions rate of CD80, CD83, CD1a and HLA-DR on the DCs surface in SIBO positive Cirrhotic patients were lower than those in SIBO negative $[(17.22 \pm 2.08) \%$ vs. $(22.13 \pm 2.34) \%,(24.65 \pm 1.47) \%$ vs. $(34.52 \pm 2.84) \%,(14.05 \pm 1.33) \%$ vs. $(17.40 \pm 3.22) \%,(81.47$ $\pm 7.56) \%$ vs. $(70.15 \pm 6.32) \%$; $(\mathrm{P}<0.05)$, (Table 2$)$

Table1: The prevalence of SIBO

\begin{tabular}{|c|c|c|c|c|}
\hline Group & Cases(n) & $\begin{array}{c}\text { Positive } \\
\text { case(n) }\end{array}$ & $\begin{array}{c}\text { The positive } \\
\text { rate (\%) }\end{array}$ & $\begin{array}{c}\chi^{2} / \text { Fisher's } \\
\text { exact test }\end{array}$ \\
\hline Healthy controls & 15 & 1 & 6.7 & \\
\hline $\begin{array}{c}\text { Cirrhosis pa- } \\
\text { tients }\end{array}$ & 47 & 22 & 46.8 & $\mathrm{P}=0.005$ \\
\hline CTP class A & 11 & 2 & 18.2 & $\mathrm{P}=0.556$ \\
\hline CTP class B & 16 & 7 & 43.8 & $\mathrm{P}=0.037$ \\
\hline CTP classC & 20 & 13 & 65 & $\mathrm{P}=0.001$ \\
\hline
\end{tabular}

Table 2: The expressions rate of CD80, CD83, CD1a and HLA-DR on the DCs surface (mean $\pm \mathrm{SD}, \%$ )

\begin{tabular}{|c|c|c|c|c|c|}
\hline Group & $\begin{array}{l}\text { Cases } \\
(\mathrm{n})\end{array}$ & CD80 & CD83 & CD1 $^{\mathrm{a}}$ & $\begin{array}{c}\text { HLA-DR } \\
\text { Healthy }\end{array}$ \\
\hline controls & 15 & $\begin{array}{c}26.79 \pm \\
3.40\end{array}$ & $\begin{array}{c}41.57 \pm \\
7.26\end{array}$ & $\begin{array}{c}25.21 \pm \\
2.48\end{array}$ & $\begin{array}{c}74.56 \pm \\
7.47\end{array}$ \\
\hline Cirrhosis & 47 & $\begin{array}{c}19.85 \pm \\
2.01^{\mathrm{a}}\end{array}$ & $\begin{array}{c}30.19 \pm \\
3.04^{\mathrm{a}}\end{array}$ & $\begin{array}{c}15.76 \pm \\
1.55^{\mathrm{a}}\end{array}$ & $\begin{array}{c}76.82 \pm \\
8.03^{\mathrm{b}}\end{array}$ \\
\hline patients & & $22.13 \pm$ & $34.52 \pm$ & $17.40 \pm$ & $81.47 \pm$ \\
SIBO negative & 25 & 2.34 & 2.84 & 3.22 & 7.56 \\
\hline \multirow{2}{*}{ SIBO positive } & 22 & $\begin{array}{c}17.22 \pm \\
2.08^{\mathrm{c}}\end{array}$ & $\begin{array}{c}24.65 \pm \\
1.47^{\mathrm{c}}\end{array}$ & $\begin{array}{c}14.05 \pm \\
1.33^{\mathrm{c}}\end{array}$ & $\begin{array}{c}70.15 \pm \\
6.32^{\mathrm{c}}\end{array}$ \\
\hline
\end{tabular}

Cirrhosis patients compared with healthy controls, ${ }^{\mathrm{a}} \mathrm{P}<0.05,{ }^{\mathrm{b}} \mathrm{P}>0.05$; SIBO positive cirrhotic patients compared with SIBO negative cirrhotic patients, ${ }^{\mathrm{c}} \mathrm{P}<0.05$.

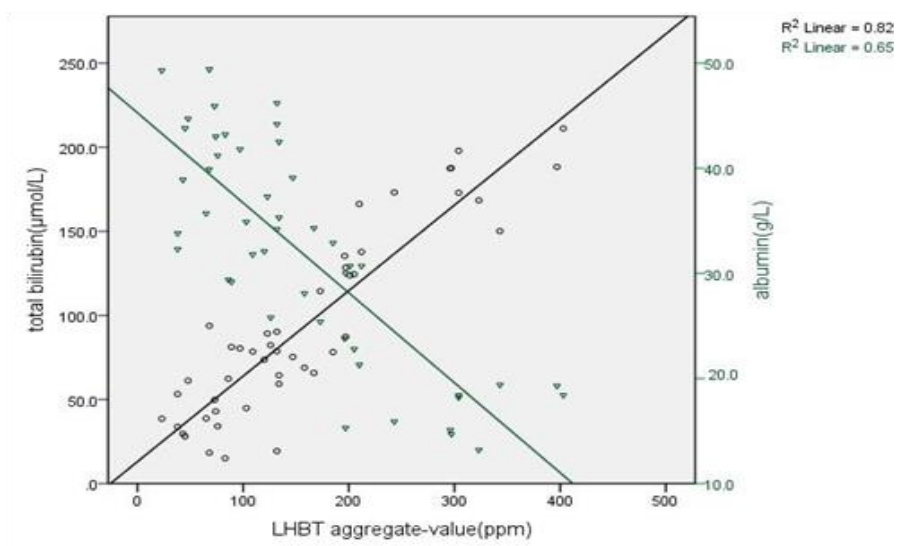

Figure 1: correlation analysis of total bilirubin, albumin and aggregate value of LHBT.

\section{Discussion}

DCs are widely distributed in many parts of the body, such as blood, liver, spleen, lymph nodes, lung, kidney and gastrointestinal tract, etc. But sparsely of DCs is observed in most human tissues. DCs selectively recognize pathogen-associated molecular patterns (PAMPs) through the toll-like receptors (TLRs) on its surface, which is common in the invasion of pathogenic microorganisms, such as bacteria and viruses. Then capture, processing and deal with and present antigen to prime naive $\mathrm{T}$ lymphocytes, induce specific T-cell responses ${ }^{[6]}$, which eliminate the infected cells or defend the body from future infection by the same source ${ }^{[7]}$. The mature DCs express high levels of major histocompatibility complex (MHC) class I and II molecules on the cells surface and costimulatory molecules. Such as human leukocyte antigen (HLA)-DR is a transmembrane MHC II family member, expressed primarily on APC, responsible for antigen presentation to $\mathrm{T}$ cells. Then activate all of the immune cells including $\mathrm{T}$ lymphocytes and $\mathrm{B}$ lymphocytes, macrophages. HLA - DR plays an important role in the immune response, so the level of its expression can be used as an important index of immune function. Furthermore, DCs also express costimulatory molecules CD80 and CD86 and induce and stimulate specific immune response. DCs play a key role in these processes that anti-pathogeny microorganism, anti-tumor immune response and maintain the body's immunological balance ${ }^{[8,9]}$. The dysfunction of DCs may play an important role in HBV persistence 
and chronic hepatitis ${ }^{[10-13]}$ and have been implicated to favor fibrosis regression $^{[14]}$. The DCs abnormalities were more severe in cirrhosis patients $^{[15,16]}$.

As we all know, the liver and gut closely linked on the structure and function. The input and output relationship of liver and intestinal are portal system and biliary system. Liver affects the function of intestinal tract through the secretion of bile and the enterohepatic circulation of bile. The harmful substances absorbed in gut through the portal circulation reach to the liver. It affects the function of the liver when was activated. Small intestinal motility disturbances and the gastrointestinal tract extravasated blood in patients with liver cirrhosis contribute to the disorder of intestinal micro-ecology, which affect the prognosis of cirrhosis ${ }^{[17]}$. And SIBO is one of the important factors. A relationship has been reported between the severity of liver diseases and the frequency of SIBO ${ }^{[18,21]}$. DCs play an important role in maintaining immune tolerance to probiotic bacteria and food antigens in gut, initiating an immune response to pathogenic microorganisms in intestinal, preventing and controlling the infection of our human body. T- Lymphocytes primed by intestinal DCs express the gut-homing receptors CCR9 and integrin relatively specific chemokine receptors, one of key factors that decided cytotoxic $\mathrm{T}$ cells to intestinal diffuse lymphoid tissue and non-lymphoid regional migration, rather than to the spleen ${ }^{[22]}$. The causal relationship between functional defects of DC and intestinal micro ecological disorder is not clear. SIBO was related to the severity of cirrhotic. Is it also related to the dysfunction of DCs, This is the aim of our study.

Lactulose is almost not absorbed in the intestine after oral. It reaches the colon and broke down by bacteria. If there are bacteria in the small intestine, the hydrogen, produced by the decomposition of lactulose, absorbed by small intestine and expired from the lungs. After oral administration of lactulose, it can detect the value of exhaled gas at different time, and can determine the growth of intestinal bacteria and gastrointestinal motility Wilberg S, et al ${ }^{[23]}$ did find (orocecal thansit time) OCTT $(97.1 \pm 22.4) \mathrm{min}$ in health volunteers by LHBT. LHBT is the most commonly used non-invasive test to diagnose SIBO. The high sensitivity and specificity have been reported for LHBT ${ }^{[24,25]}$ Zhong, et $\mathrm{al}^{[26]}$ found that LHBT was performed in 64 patients with chronic liver diseases and 40 health subjects. The amount of hydrogen produced in 3 hours in LHBT positive patients were much higher than those in LHBT negative patients and healthy control. We used peak of hydrogen concentration and LHBT aggregate-value in 90 minutes to evaluate the growth of the small intestine bacteria.

In our study, the prevalence of SIBO in cirrhotic was $46.8 \%$, which was similar to other related literature ${ }^{[27,28]}$. Which may be related to the different detection methods and research subjects? The prevalence of SIBO in patients with decompensated cirrhosis (Child-Pugh B, C) was significantly higher than that of compensated (Child-Pugh A), which reached obviously statistical significance $(\mathrm{P}=0.043)$. The prevalence of SIBO in patients with cirrhosis increased with the severity of cirrhosis. Pande $\mathrm{C}$ et $\mathrm{a}^{\left[{ }^{[18]}\right.}$. studied the best cut-off of serum bilirubin was $>2 \mathrm{mg} / \mathrm{d}$ L predicting SIBO with accuracy $74 \%$, if the combination of ascites and serum bilirubin $>2 \mathrm{mg} / \mathrm{d}$ L prediction SIBO accuracy up to $82 \%$. SIBO was independently associated with serum bilirubin and ascites. We found that aggregate value of hydrogen in 90 minutes were positively correlated with bilirubin, and were negatively correlated with albumin. As the index of clinical evaluation liver injury degree, bilirubin and albumin also can reflect the growth of small intestinal bacteria. The mechanism is probably that SIBO give rise to endotoxemia and then make bilirubin excretion disorder more serious; SIBO could lead to malabsorption, and then cause the hypoproteinemia condition aggravation.

We found that the expression of HLA-DR on the surface of DCs in HBV cirrhotic patients and healthy controls was no statistical significance $(\mathrm{P}>0.05)$. The expression of CD1a, CD80, CD83 on the surface of DCs in cirrhotic patients were all significant lower than that in healthy controls $(\mathrm{P}<0.01)$. The expression rate of CD1a, HLA-DR, CD80 and CD83 on the DCs surface in SIBO positive cirrhotic patients was lower than those in SIBO negative $(\mathrm{P}<0.05)$, indicate the expression of DCs phenotype in cirrhotic patients was different in SIBO positive and negative. Although often regarded as a marker for immature dendritic cells, in many in vitro systems, CD1a is expressed equally strongly on immature and mature dendritic cells. CD1a is expressed predominantly in dendritic cells and few other cell types ${ }^{[30]}$. So we usually use CD1a positive cells to reflect the number of $\mathrm{DCs}^{[31,32]}$. Cell surface CD83 is rapidly upregulated and highly expressed by activated CD4+ T cells, CD8+ T cells, and B cells. The high-density CD83 expression is a marker for human DCs maturation. And T-cell stimulatory capacity is the most powerful in mature DCs.

Treg cells is the main immunosuppressive cells in the body and can inhibit the maturity of the DCs. Q-Zhang et $\mathrm{at}^{[4]}$ found that compared with DCs control, the expression of CD83, andCD80 of DCs in the peripheral blood of 18 healthy controls and $15 \mathrm{CHB}$ patients was significantly decreased when cocultmed with Treg cells, while the expression of HLA-DR was no significant statistical significance. Studies have shown that the number of DCs decreased with the disease progression of HBV infection, which characterized DCs number in chronic hepatitis B was lower than that in healthy persons, but it was higher than that in cirrhosis. The number of DCs decreased in cirrhotic patients with hepatitis B may be several reasons. First, the generation of DCs precursors in bone marrow decreased due to the infection of HBV. Second, HBV-infection may result in increased apoptosis of DCs. Then, it is also possible that these DCs were activated and redistributed in liver tissue ${ }^{[33,34]}$.

The different expressions of DCs phenotype are connecting with DCs impaired function, different sources different maturity. The DCs phenotype in cirrhosis with or without SIBO is different, which reason is not clear yet. But the functional differences in DCs may be a factor that the intestinal bacterial into the blood, lymph and liver, which is the meaning of our study. Certainly, the connection between DCs in cirrhosis complications and SIBO still needs further research.

\section{Supported By}

1. The Foundation for Key Science and technology research project of Henan Province, No: 152102310002.

2. Science and technology research project of Zhengzhou, NO: 20140460.

\section{Conflicts of Interest: No}




\section{References}

1. Muñoz, L., José Borrero, M., Ubeda, M., et al. Interaction Between Intestinal Dendritic Cells and Bacteria Translocated From the Gut in Rats With Cirrhosis. (2012) Hepatology 56(5): 1861 -1869.

2. Tsoumakidou, M., Koutsopoulos, A.V., Tzanakis, N., et al. Decreased small airway and alveolar CD83 + dendritic cells in COPD. (2009) Chest 136(3): 726-733.

3. Zheng, S., Tang, Y.M., Yang, J.H. Clinical implication of peripheral blood dendritic cell subsets in cirrhotic patients with hepatitis B virus infection. (2014)Journal of practical hepatology 17(3): 275-278.

4. Zhang, Q., Pang, G.J., Shen, S.J., et al. Effect of CD4+ CD25+Treg on maturation of DC in chronic hepatitis B patients. (2014) Journal of clinical and experimental medicine 13(8): 601-607.

5. Chinese Society of Hepatology and Chinese Society of Infectious Diseases, Chinese Medical Association. The guideline of prevention and treatment for chronic hepatitis B (2010 version). (2011) Chin J Hepatol 19(1): 13-24.

6. Gowans, E.J., Roberts, S., Jones, K., et al. A phase I clinical trial of dendritic cell immunotherapy in HCV-infected individuals. (2010) J Hepatol 53(4): 599-607.

7. Hu, J., Wan, Y. Tolerogenic dendritic cells and their potential applications. (2011) Immunology 132(3): 307-314.

8. Holmannova, D., Kolackova, M., Kune, P., et al. Impact of cardiac surgery on the expression of CD40, CD80, CD86 and HLA-DR on B cells and monocytes. (2015) Perfusion.

9. Yao, V., Platell, C., Hall, J.C. Dendritic cells. (2002) ANZ J Surgery 72(7): 501- 506

10. Kurose, K., Akbar, S.M., Yamamoto, K., et al. Production of antibody to hepatitis B surface antigen (anti-HBs) by murine hepatitis B virus carriers: neonatal tolerance versus antigen presentation by dendritic cells. (1997) Immunology 92(4): 494-500.

11. Wang, K., Fan, X., Fan, Y., et al. Study on the function of circulating plasmacytoid dendritic cells in the immunoactive phase of patients with chronic genotype B and C HBV infection. (2007) J Viral Hepat 14(4): 276-282.

12. Chisari, F.V., Ferrari, C. Hepatitis B virus immunopathogenesis. (1995) Annual Review of Immunology 13: 29-60.

13. Ma, Y.J., He, M., Han, J.A, et al. A clinical study of HBsAg-activated dendritic cells and cytokine-induced killer cells during the treatment for chronic hepatitis B. (2013) Scandinavian journal of immunology 78(4): 387-393.

14. Blois, S.M, Piccioni, F., Freitag, N., et al. Dendritic cells regulate angiogenesis associated with liver fibrogenesis. (2014) Angiogenesis 17(1): 119-128.

15. Chen, W.W., Shi, M., Xin, S.J, et al. The research progress of therapeutic DCs vaccine in Chronic viral infection. (2007) Natl Med J China 87: $1582-1584$

16. Beckebaum, S., Cicinnat,i V.R., Zhang, X., et al. Hepatitis B virus-induced defect of monocyte-derived dendritic cells leads to impaired T helper type 1 response in vitro: mechanisms for viral escape. (2003) Immunology 109(4): 487-495.

17. Goel, A., Gupta, M., Aggarwal, R. Gut microbiota and liver disease. (2014) Gastroenterol Hepatol 29(6): 1139-1148.
18. Pande, C., Kumar, A., Sarin, S.K. Small intestinal bacterial overgrowth in cirrhosis is related to the severity of liver disease. (2009) Alimentary Pharmacology \& Therapeutics 29(12): 1273-1281.

19. Li, S.L., Liu, X.J., Zhou, H.T. The relationship between hepatic cirrhosis and small intestine bacterial Overgrowth. (2014) China modern medicine 21: 58-60.

20. Lian, H.Y., Luo, Y.H. The correlation of clinical research between liver cirrhosis and small intestinal bacterial overgrowth. (2015) Medical Information 28: 67.

21. Jun, D.W., Kim, K.T., Lee, O.Y., et al. Association between small intestinal bacterial overgrowth and peripheral bacterial DNA in cirrhotic patients. (2010) Dig Dis Sci 55(5): 1465-1471.

22. Eksteen, B., Mora, J.R., Haughton, E.L., et al. Gut homing receptors on CD8 T cells are retinoic acid dependent and not maintained by liver dendritic or stellate cells. (2009) Gastroenterology 137(1): 320-329.

23. Wilberg, S., Pieramico, O., Malfertheiner, P. The H2-lactulose breath test in the diagnosis of intestinal transittime. (1990) Leber Magen Darm 20(3): 129-137.

24. Kerlin, P., Wong, L. Breath hydrogen testing in bacterial overgrowth of the small intestine. (1988) Gastroenterology 95(4): 982-988.

25. Rhodes, J.M., Middleton, P., Jewell, D.P. The lactulose hydrogen breath test as a diagnostic test for small-bowel bacterial overgrowth. (1979) Scand J Gastroenteml 14(3): 333-336.

26. Zhong, L., Liu, W., Rong, L., et al. Chronic Liver Disease and Small Intestinal Bacterial Overgrowth: Results of Hydrogen Breath Test. (2006) Chin J Gastroentero 11(2): 96-98.

27. Sanchez, E., Casafont, F., Guerra, A., et al. Role of intestinal bacterial overgrowth and intestinal motility in bacterial translocation in experimental cirrhosis. (2005) Rev Esp Enferm 97(11): 805-814.

28. Bauer, T.M., Steinbrückner, B., Brinkmann, F.E, et al. Small intestinal bacterial overgrowth in patients with cirrhosis: prevalence and relation with spontaneous bacterial peritonitis. (2001) Am J Gastroenterol 96(10): 2962-2967.

29. Bures, J., Cyrany, J., Kohoutova, D., et al. Small intestinal bacterial overgrowth syndrome. (2010) World J Gastroenterol 16(24): 29782990.

30. Hilly, O., Rath-Wolfson, L., Koren, R., et al. CD1a-positive dendritic cell density predicts disease-free survival in papillary thyroid carcinoma. (2015) Pathology - Research and Practice 211(9):652-656.

31. Tanimoto, K., Akbar, S.M., Michitaka, K., et al. Antigen-presenting cells at the liver tissue in patients with chronic viral liver diseases: CD83-positive mature dendritic cells at the vicinity of focal and confluent necrosis. (2001) Hepatol Res 21(2):117-125.

32. Rouard, H., Leon, A., Klonjkowski, B., et al. Adenoviral transduction of human "clinical grade" immature dendritic cells enhances costimulatory molecule expression and T-cell stimulatory capacity. (2000) J Immunol Meth 241(1-2): 69-81.

33. Duan, X.Z., Zhuang, H., Wang, M., et al. Decreased numbers and impaired function of circulating dendritic cell subsets in patients with chronic hepatitis B infection (R2). (2005) Journal of Gastroenterology and Hepatology 20(2): 234-242.

34. Cella, M., Jarrossay, D., Facchetti, F., et al. Plasmacytoid monocytes migrate to inflamed lymph nodes and produce large amounts of type I interferon. (1999) Nat. Med 5(8): 919-923. 